\title{
Fluorometric immunoassay for detecting the plant virus Citrus tristeza using carbon nanoparticles acting as quenchers and antibodies labeled with CdTe quantum dots
}

\begin{abstract}
Cadmium-telluride quantum dots (QDs) were conjugated to an antibody (Ab) against Citrus tristeza virus (CTV), while the coat protein (CP) of the CTV was immobilized on the surface of carbon nanoparticles (CNPs). Following immunobinding of the QD-Ab and the CP-loaded CNPs, the fluorescence of the CdTe QDs was quenched by the CNPs. This effect was exploited to design a detection assay for the CTV which was found more sensitive and specific than the existing enzyme linked immunosorbent assay (ELISA). The limit of detection was measured at about $220 \mathrm{ng} \cdot \mathrm{mL}^{-1}$ of CTV. The Stern-Volmer plot of the CNPsQD quencher pair showed a positive deviation from linearity which was ascribed to the presence of both static and dynamic quenching.
\end{abstract}

Keyword: Bioassay; Competitive quenching; Stern-Volmer relationship; ELISA; TEM; FTIR; CdTe; Synthesis; Bioconjugation 